
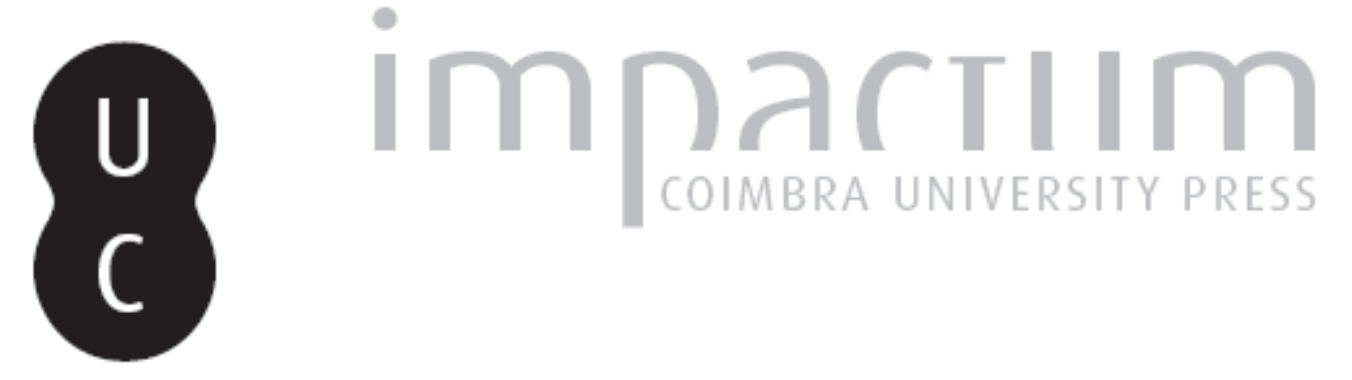

\title{
A sepultura do séc. II de um guerreiro com espada: (Morgado Dona Menga - Tavira) Autor(es): $\quad$ Mendes, David Calado
}

Publicado por: Imprensa da Universidade de Coimbra

URL persistente:

URl:http://hdl.handle.net/10316.2/45394

DOI:

DOI:https://dx.doi.org/10.14195/1647-8657_38_9

Accessed : $\quad$ 26-Apr-2023 15:30:40

A navegação consulta e descarregamento dos títulos inseridos nas Bibliotecas Digitais UC Digitalis, UC Pombalina e UC Impactum, pressupõem a aceitação plena e sem reservas dos Termos e Condições de Uso destas Bibliotecas Digitais, disponíveis em https://digitalis.uc.pt/pt-pt/termos.

Conforme exposto nos referidos Termos e Condições de Uso, o descarregamento de títulos de acesso restrito requer uma licença válida de autorização devendo o utilizador aceder ao(s) documento(s) a partir de um endereço de IP da instituição detentora da supramencionada licença.

Ao utilizador é apenas permitido o descarregamento para uso pessoal, pelo que o emprego do(s) título(s) descarregado(s) para outro fim, designadamente comercial, carece de autorização do respetivo autor ou editor da obra.

Na medida em que todas as obras da UC Digitalis se encontram protegidas pelo Código do Direito de Autor e Direitos Conexos e demais legislação aplicável, toda a cópia, parcial ou total, deste documento, nos casos em que é legalmente admitida, deverá conter ou fazer-se acompanhar por este aviso.

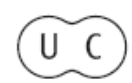


UNIVERSIDADE DE COIMBRA

FACULDADE DE LETRAS

\section{CONIMBRIGA}

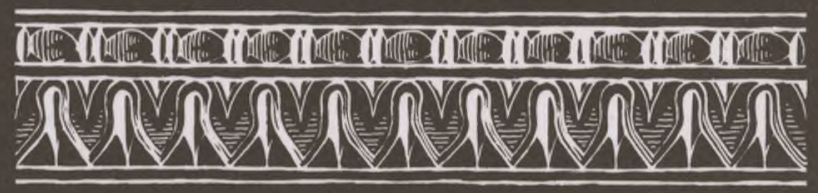

VOLUME XXXVIII - 1999 
DAVID CALAdo MENDES

Técnico Superior da Direcção Regional de Faro do IPPAR

\author{
A SEPULTURA DO SÉC. II DE UM GUERREIRO COM ESPADA \\ (MORGADO DONA MENGA - TA VIRA) \\ "Conimbriga” XXXVIII (1999) p. 215-223
}

RESUMO: Entre os agricultores do Algarve são comuns as histórias de achados de sepulturas com armas em ferro. No Morgado Dona Menga, Tavira, a descoberta de uma espada, quando da abertura de uma fossa, originou uma intervenção arqueológica de emergência a fim de caracterizar a sepultura.

O túmulo, perfeitamente orientado Norte-Sul, era constituído por três elementos distintos, uma cista aparelhada em opus testaceum sobreposta por um covai forrado por tegulce e à superfície um cairn raso com fortes vestígios de queima.

O espólio da cista era formado por um copo em vidro, típico do séc. I-II e por uma espada de dois gumes, aparentemente não romana, mas similar às espadas germânicas do Ferro Romano I.

A orientação N-S da cista, o uso de cairn e o fogo ritual sobre a sepultura são comuns nas necrópoles germânicas de finais do Ferro Céltico e Ferro Romano, como Sönderholm, Himlingöje e Juellinge.

A possibilidade da existência de comunidades germânicas no extremo SW peninsular durante os séculos I e II da nossa era é viabilizada por três acontecimentos históricos:

1. A movimentação da legião Gemina do Reno para a Península, em aproximadamente $74 \mathrm{DC}$;

2. As invasões dos Mauri no séc. II, que originaram a deslocação para o Sul da península da legião Gemina e tropas vindas da Macedònia;

3. A abertura das fronteiras por Marcus Aurelius, como forma de repovoar os territórios do Império, após as violentas pestes do séc. II. 
ABSTRACT: In Tavira, Algarve, was newly discovered a warrior's grave a short sword and a glass from the I ou II century AD.

The grave was perfectly oriented North-South and was formed by three main elements: A cist in opus testaceum of lateres crudi covered by heavy stone slabs, superposed by a ditch lined with tegulce. The surface of the grave was delimited by a flat cairn with signs of ritual fires. The orientation of the grave, the cairn and ritual fires, resemble the Germanic graves from late Celtic and Roman Iron Age. Moreover, the deposition of weapons in graves is a most seldom element in the Roman world. In addition, the sword of Tavira seems to be a typical Germanic double edged sword from the early Roman Iron Age.

The possible existence of Germanic colonies in the extreme SW of the empire so early as the I or II century AD could be historically explained by three facts:

1. The displacement of the legio Gemina from the limes to Iberia in 74 $\mathrm{AD}$;

2. The Mauri invasions of the II century, that forced the moviment of the legio Gemina to the Southern Iberia as well as the arrival of Roman troops from Macedonia;

3. The opennig of the limes by Marcus Aurelius after the violent plagues of the II century AD. 


\section{A SEPULTURA DO SÉC. II DE UM GUERREIRO COM ESPADA (MORGADO DONA MENGA - TAVIRA)}

\section{I - INTRODUÇÃO}

Quando da abertura de uma vala de drenagem no Morgado Dona Menga, Luz de Tavira, Algarve, foi posta a descoberto a sepultura de um guerreiro acompanhado da sua curta espada de ferro de dois gumes, e de um copo de vidro.

O copo de vidro (Isings 35) é do séc. II d. C., e a espada mostra grandes semelhanças com as espadas germânicas de dois gumes do Ferro Romano I (0-200 d. C.).

Embora a cista (forma e materiais) fosse tipicamente romana, a sua orientação e cobertura por tumulus, apontam para inspirações exógenas, com algumas semelhanças conceptuais às das sepulturas do Ferro Romano do sul da Germânia livre.

A estrutura parece assim sugerir um sincretismo entre forma e materiais de construção de origem romana, e conceitos religiosos não clássicos.

\section{II - LOCALIZAÇÃO E AMBIENTE GEOGRÁFICO}

O morgado Dona Menga, ou da Belota, situa-se no sítio do Fundo, freguesia da Luz de Tavira, concelho de Tavira, distrito de Faro. As coordenadas Info-Gauss do local são: $\mathrm{M}=234,9$ e $\mathrm{P}=014,9$.

O sítio era conhecido de anteriormente pela riqueza do espólio de superfície, e necrópole, datáveis da época romana $\mathrm{L}^{1}$

1 Alarcão, Jorge; Roman Portugal Voi. Wiltshire 1988, pag. 208. 
A altimetria regista cotas de 49 metros no cimo das colinas, enquanto a sepultura, num pequeno vale, sobre o leito de um antigo ribeiro, se encontrava na cota dos 30 metros.

A geomorfologia do local é formada por um relevo suave com pequenas colinas arredondadas. O terreno é argiloso, de aluvião, com excelentes características para a agricultura, sobrepondo-se a um substrato aluvionar arenoso, estéril, de cor amarelada, cravejado por pequenos blocos de caliço mole.

Nos vales correm pequenos ribeiros sazonais cujo curso tem sido progressivamente alterado por terraplenagens e canalizações.

Do topo das colinas é visível, a $3.5 \mathrm{Km}$ para SE, a Luz de Tavira, eventual zona de implantação da antiga cidade romana de Balsa.

\section{III - ESCAVAÇÃO, ESTRATIGRAFIA E DESCRIÇÃO DAS ESTRUTURAS}

A estrutura tumular foi parcialmente destruída quando da abertura da vala de drenagem. As condições climatéricas sob as quais correu a escavação de emergência não foram as melhores. As chuvas torrenciais provocavam constantes inundações da vala, no fundo da qual se encontrava a sepultura, situação minorada pela execução de um pequeno desvio das águas.

A quadrícula de escavação, com três metros de lado, foi orientada N-S. Utilizou-se o sistema clássico de coordenadas X-Y-Z.

A zona da quadrícula foi escavada até à superfície estéril em camadas mecânicas artificiais de $0,05 \mathrm{~m}$ de espessura. Todas as massas provenientes da cista foram joeiradas a seco.

A uma profundidade de aproximadamente $50 \mathrm{~cm}(Z=1.6)$ foi encontrado um tumulus raso, calcetado, rectangular, orientado N-S, que cobria e delimitava o covai, e definia a superfície contemporânea da sepultura. Sobre o tumulus parecia ter sido acendida uma fogueira.

O covai entre o tumulus e a cista tinha uma espessura aproximada de óOcm $(Z=1.6$ - 1.0), e estava revestido por tegulae dispostas na vertical, encostadas à parede, formando um forro. Nas massas do covai foram recuperados fragmentos de um aryballos em vidro policromo (Isings 61) datado da segunda metade do séc. I.

A cista, aparelhada em opus testaceum de lateres crudi de dimensões variáveis, era coberta por três grandes lajes em calcário, reapro- 
veitadas, e estava rigorosamente orientada N-S. Em cada uma das paredes laterais, no extremo $\mathrm{S}$, existia uma pequena câmara.

As dimensões internas da cista eram: $1.97 \mathrm{~m}$ de comprimento, $0.53 \mathrm{~m}$ de largura e $0.50 \mathrm{~m}$ de fundura. As dimensões externas eram: $2.46 \mathrm{~m}$ de comprimento, $0.99 \mathrm{~m}$ de largura e $0.59 \mathrm{~m}$ de altura.

\section{IV - O ESPÓLIO}

\section{Espólio Osteológico}

Logo que descoberta, a sepultura foi profanada por um grupo de trabalhadores agrícolas com o intuito de encontrar " libras de ouro". O esqueleto foi completamente retirado da cista, os ossos longos e dentes rapinados, e o resto espalhado ao redor da sepultura e fortemente pisoteado.

Entre os pequenos fragmentos do esqueleto encontrou-se um processus mastoideus, classificado com um factor +1 ou $+2^{2}$.

Também foi encontrado um segundo molar inferior (FDI47). Este dente possui um término de calcificação entre os doze anos e os treze anos e três quartos, apresentava um forte desgaste lateral, e uma ampla cáries que se desenvolvia a partir do colo. Os sulcos estavam bem delimitados e as cúspides pouco desgastadas. O desgaste foi classificado como o equivalente ao grau 2 da escala de Topinard ${ }^{3}$, e proveniente do atrito da acção mastigatória, o que levou a classificar o indivíduo como pertencente aos grupos biológicos adultus ou maturus, conforme o definido por Trevor Anderson 4 .

Parece, portanto, tratar-se dos restos mortais de um indivíduo do sexo masculino, com uma idade compreendida entre os 25 e 55 anos.

2 Workshop of Europen Anthropologists; "Recomendation for Age and Sex Diagnosis of Skeletons" in Journal of Human Evolution Voi. 9 N. ${ }^{\circ} 7$ November 1980, pag. 523.

3 Picosse, Milton; Anatomia Dentária. São Paulo 1977, pag. 159-161 e 299-302.

4 Anderson, Trevor; " The churchyard of the Folkebibliotekstomt (Library site).

An Interim Osteological Report" in Meddelser $N .^{\circ}$ 2, Trondheim 1986, pag. 4-5. 


\section{Espólio Arqueológico}

Os elementos de vidro do espólio arqueológico foram classificados e datados por Adília Alarcão.

Nas massas que enchiam o covai foram encontrados fragmentos de um aryballos policromo (Isings 61) datado da segunda metade do séc. I.

$\mathrm{Na}$ pequena câmara, na parede leste da cista, foi encontrado um copo em vidro (Isings 35) do séc. II.

Ainda no interior da cista estavam um imbrex, uma pedra de amolar (rapinada e não recuperada), e uma espada de ferro, curta, de dois gumes, aparentemente de origem alóctone.

A raridade deste achado levou à tentativa de enquadramento da espada numa tipologia, verificando-se uma possível inserção entre as espadas germânicas do Ferro Romano Antigo (0-200 d. C.), quando a espada longa, de tradição La Téne, é substituída pela espada curta de dois gumes ${ }^{5}$.

Curiosamente, o Ferro Romano I é o único período em que foi utilizado este tipo de espadas. Com a transição para o Ferro Romano II (200-400 d.C.), as espadas curtas são substituídas por espadas longas também de dois gumes.

\section{V - O TÚMULO E O RITUAL FUNERÁRIO}

A estrutura sepulcral estava perfeitamente orientada N-S, e era constituída por três grandes conjuntos de elementos:

a. a cista, aparelhada em opus testaceum de lateres crudi, coberta por três pesadas lajes de pedra;

b. o covai, forrado por tegulae, e no enfiamento da cista;

c. o tumulus raso, com indícios de fogo.

Se parece pacífica a aceitação de uma técnica de construção e materiais de origem romana para a cista e forro de covai, bem como para parte do espólio arqueológico; o conjunto formado pela orientação

$5 \quad$ Hougen, Björn; Rom og Norden, Oslo 1936, pag. 108; Munksgaard, Elisabeth; “ Jemalder” in Je g ser paa oldsager, direç̧ão de Mogens Ruud, Copenhagen 1965, pag. 231, 248. 
da sepultura, tumulus, e parte do espólio, parece difícil de inserir no mundo Clássico.

Tentou-se assim testar a hipótese de se tratar de um fenómeno de sincretismo cultural.

Recorrendo-se à comparação dos elementos: orientação, espólio de armas, e tumulus, pretendeu-se aventar hipóteses para a explicação de um eventual fenómeno sincrético. Neste contexto, constataram-se similaridades com as necrópoles do Ferro Romano do Sul da Dinamarca e Norte da Alemanha, como as necrópoles de Sónderholm, Himlingöje e Juellinge. Este tipo de necrópoles é caracterizado por espólio que podia conter armas, orientação N-S das cistas de inumação, e usual cobertura por tumulus. ${ }^{6}$

O fogo purificador sobre as sepulturas, parece ser um fenómeno largamente disperso, existindo evidência da sua utilização no norte da Hispania a partir do séc. $V^{7}$, o que provavelmente mais não significará que o retomar de um ritual caído em desuso pelo crescimento do Cristianismo.

A combinação da orientação N-S de cistas de tipologia romana, e espadas como espólio, não parece ser um elemento novo em Portugal.

Nos anos de 1888-1889, Francisco de Paula e Oliveira explorou várias necrópoles, da época romana, na zona de Cascais.

Das dezenas de cistas exploradas, todas estavam orientadas E-W, com excepção de duas cistas orientadas $\mathrm{N}-\mathrm{S}$, na extremidade $\mathrm{W}$ da necrópole da Abuxarda. Uma dessas sepulturas orientadas N-S possuía provavelmente uma espada:

"Dans une de ces tombes, orientée nord-sud, j'ai trouvé un objet enfer très oxidé, peut-être le fragment d'une épée". 8

6 Para mais completa descrição das estruturas tumulares do Ferro Romano no sul da Germânia livre podem ser consultados: Hansen, Ulla Lund; série de artigos in Arkeologisk haandbog, direcção de Mogens Rud, Copenhagen 1979, pag. 125-127; 144; 238-242; Hagen, Anders; Norges Oldtid, Oslo 1983, pag. 291-293; Slomann, Wenche; Folkevandringstiden i Norge, Oslo 1968, pag. 132

7 Heers, Jacques; O mundo Medieval, Lisboa 1976, pag. 28-29

8 Paula e Oliveira, F. de; "Antiquités Préhistoriques et Romaines des environs de Cascaes" in Comunicações da Comissão dos Trabalhos Geológicos de Portugal Tom. II - Facs. I, 1889, pag. 88-89 


\section{VI - INTEGRAÇÃO HISTÓRICA}

A problemática de sugerir a existência de colónias germânicas no SW do Império Romano no séc. II, parecia a priori chocar com a interpretação tradicional das fontes históricas. Este choque é, contudo, só aparente. A existência e origem desses eventuais colonos pode ser perfeitamente enquadrada por três acontecimentos, historicamente bem documentados:

1. o retomo da VII Legião Gemina da zona do Reno em aproximadamente 74 d. C.; 9

2. as invasões dos Mauri, que atravessaram o estreito e tomaram o sul da actual Andaluzia, provocando a movimentação para essa zona de pelo menos uma legião romana, a VII legião Gemina, e tropas vindas da Macedonia; 1011

3. o imperador Marcus Aurelius, em resposta à dizimação da população pela peste, abre as fronteiras do Império aos colonos de além limes que se pretendam estabelecer no seu interior. ${ }^{11}$

\section{VII - CONCLUSÃO}

No Morgado Dona Menga, nas proximidades da suposta localização da antiga cidade romana de Balsa, foi acidentalmente descoberta uma "sepultura de guerreiro".

O esqueleto, apesar de muito maltratado, indicia que se trataria de um indivíduo de sexo masculino, do grupo etário adultus, ou eventualmente maturus.

O espólio da sepultura era constituído por um copo em vidro (Isings 35) datado do séc. II d. C., um imbrex, uma pedra de amolar, e uma curta espada de dois gumes, que não aparenta ser um gladius ou uma spatha. A análise comparada de tipologias mostrou que a espada pode ser enquadrada no conjunto de espadas germânicas do Ferro

9 Roldán Hervas, Jose Manuel; Hispania y el ejercito romano, Salamanca 1974, pag. 202. idem; Historia de Roma, Salamanca 1995, pag. 343-344

10 Roldán Hervas, J. M. 1974 pag. 204

11 Castillo, Arcadio del; El Imperio Romano durante las dinastias Flavia y Antonina (69-192 d. de C.) in Manual de Historia Universal, Vol. IV - Roma, Madrid 1983 pag. 250. Roldán Hervas, J.M.; 1995, pag. 344. 
Romano I (0-200 d. C), o que concorda com a datação do copo em vidro encontrado na sepultura, e os fragmentos de aryballos (Isings 61), datado do séc. I, encontrados nas massas do covai.

A sepultura, apesar de apresentar uma técnica de construção romana para a cista (aparelho em opus testaceum de lateres crudi), possuía alguns elementos estranhos às sepulturas romanas contemporâneas: orientação precisa N-S, e cobertura por tumulus. O inusitado da situação levou a considerar que se poderá tratar de um exemplo de sincretismo cultural, sugerindo influências das necrópoles do Sul da Germânia livre, do Ferro Romano.

A eventual existência de grupos germânicos no SW do Império durante o século II poderia ser explicada pelos três factores atrás mencionados:

1. o retorno da VII Legião Gemina da zona do Reno em, aproximadamente, 74 d. C.;

2. as invasões dos Mauri do último quartel do séc. II e, como resposta a movimentação de tropas estacionadas na Macedonia para a Península;

3. o imperador Marcus Aurelius, que abre as fronteiras do Império aos colonos de além-limes.

A diminuta presença de elementos materiais do séc. II de possível origem ou influência germânica, no SW do Império, não deve ser utilizada, a priori, como elemento dissuasor de uma possível permanência de grupos germânicos organizados na zona. A afirmação étnica poderá não corresponder a diferenças muito nítidas na cultura material, bem como algum do material arqueológico poderá ter sido classificado como "tardo-romano".

A evidência empírica mostra que, no Morgado Dona Menga, foi enterrado um homem, seguindo rituais bastante estranhos ao mundo romano. A execução de um rito de passagem implica a existência de um grupo de indivíduos com um credo comum.

Sendo a primeira vez que é levantada a hipótese da permanência de colonos de origem teutónica no SW da Península, durante o século II d. C., parece, no entanto, já terem sido descobertas, anteriormente, outras sepulturas com características análogas.

Os meus agradecimentos a: Adília Alarcão, pela classificação e datação do espólio em vidro; Jorge Alarcão, pelas sugestões de alteração ao texto original, o que permitiu a sua significativa melhoria; e a Raul Lima, sem cujo apoio e interesse a intervenção de salvamento da "sepultura de guerreiro" do Morgado Dona Menga não se teria realizado. 


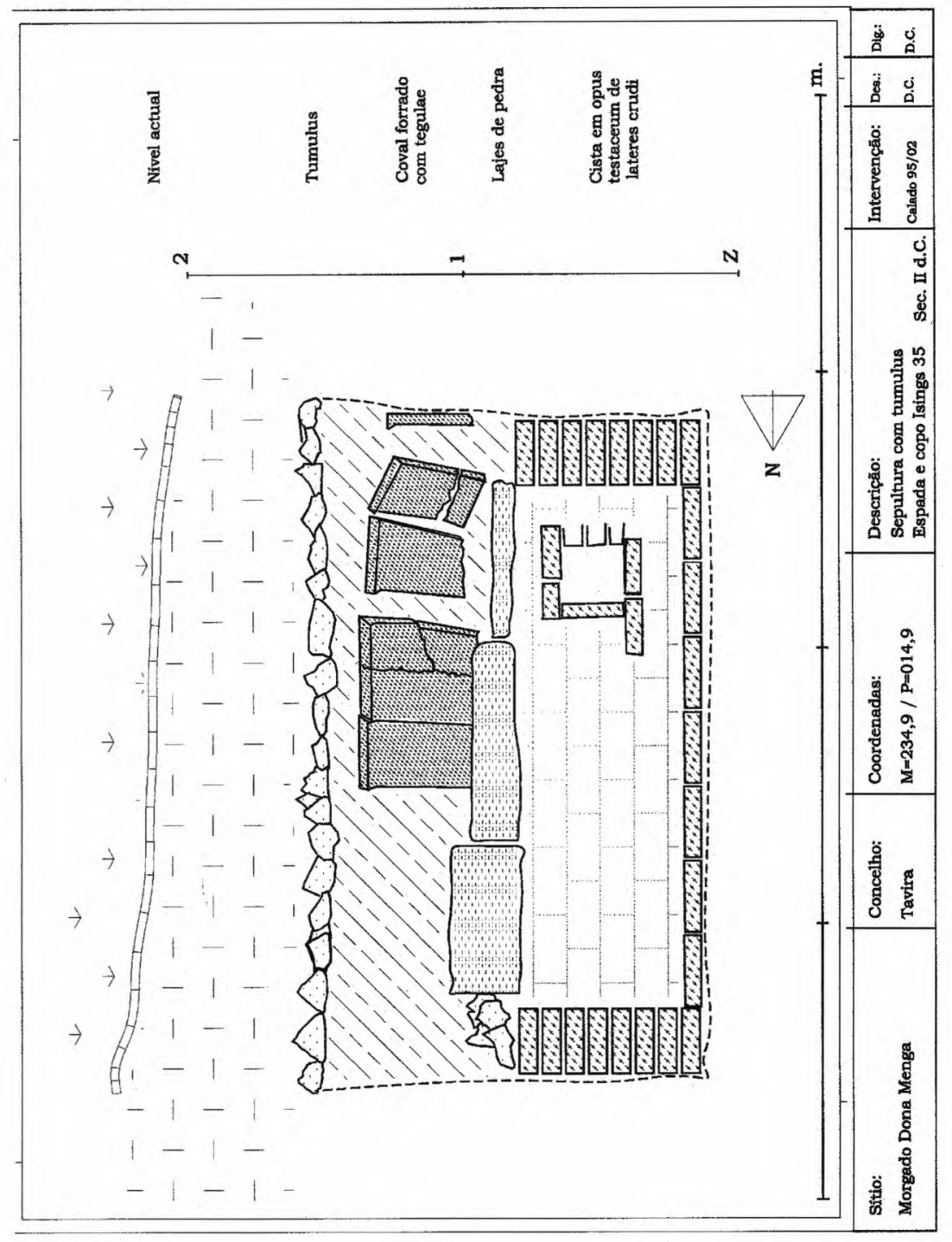




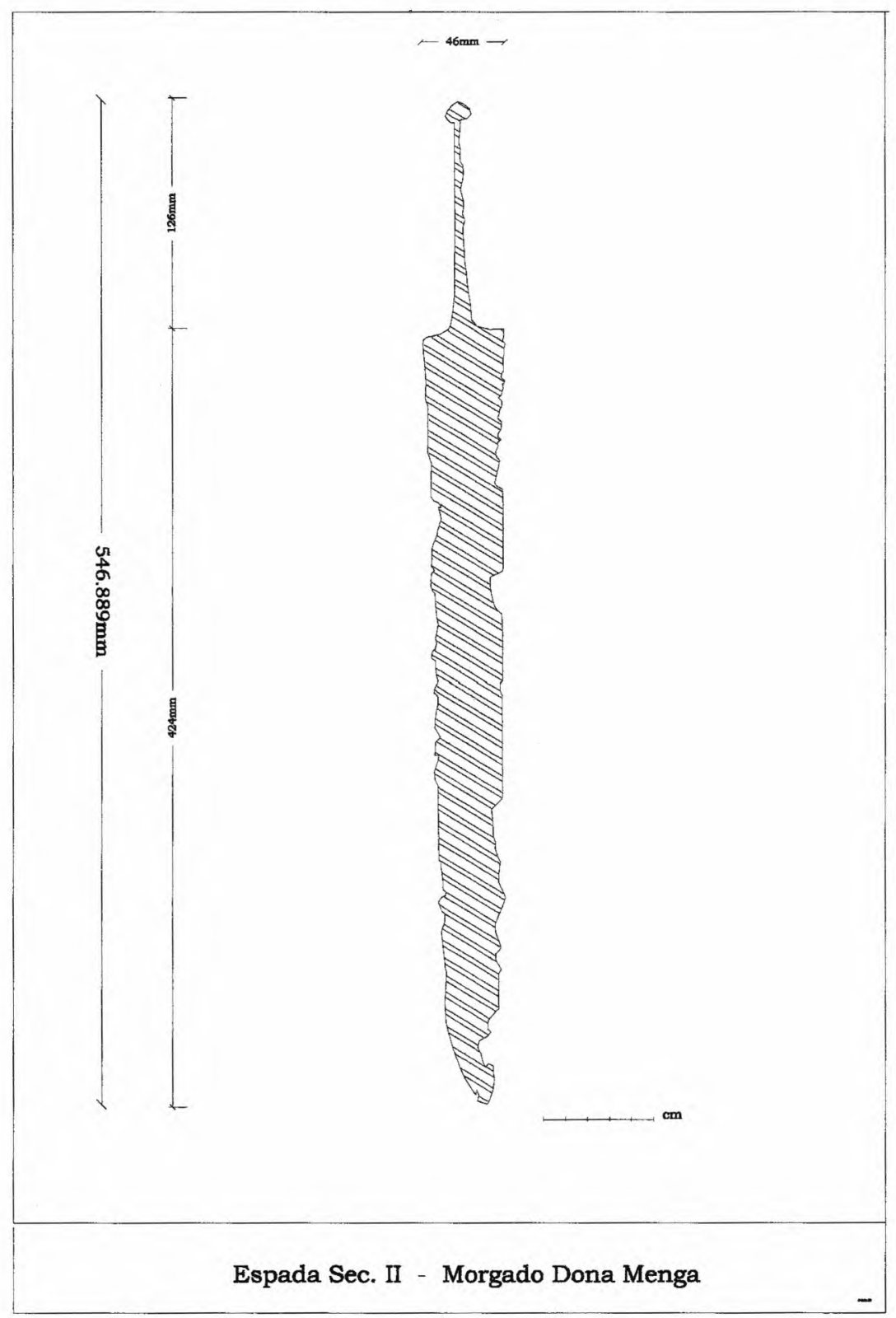




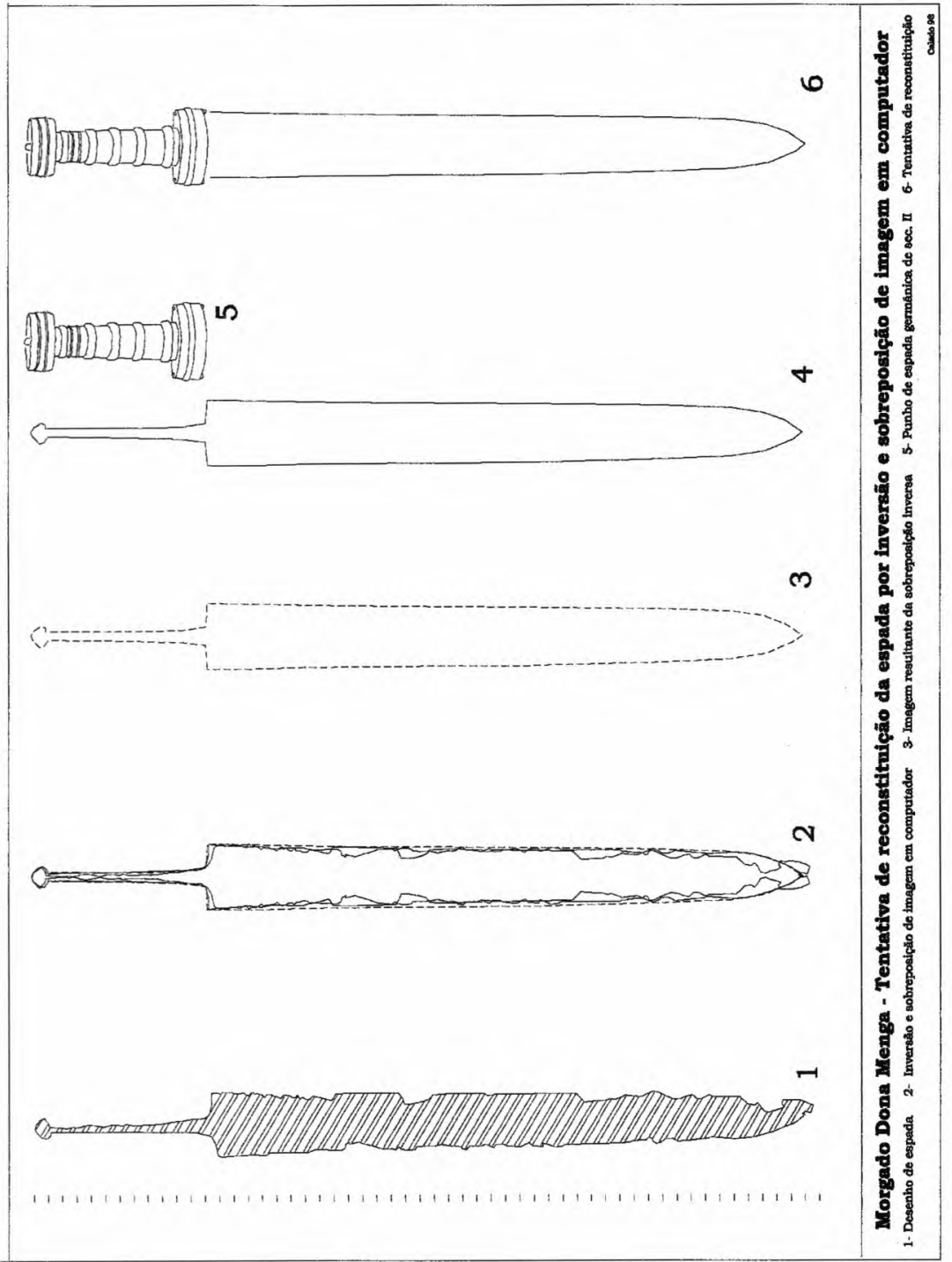




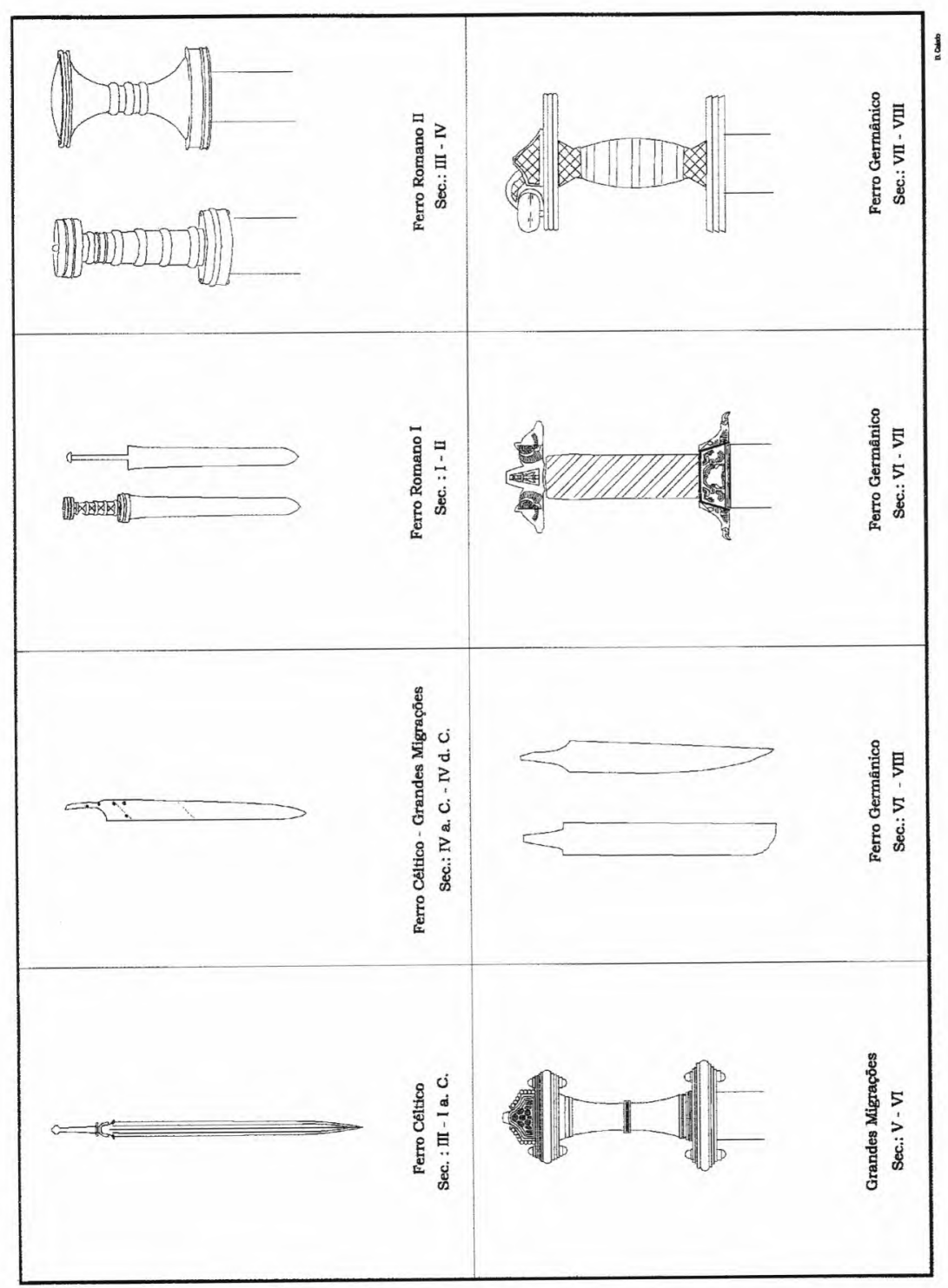




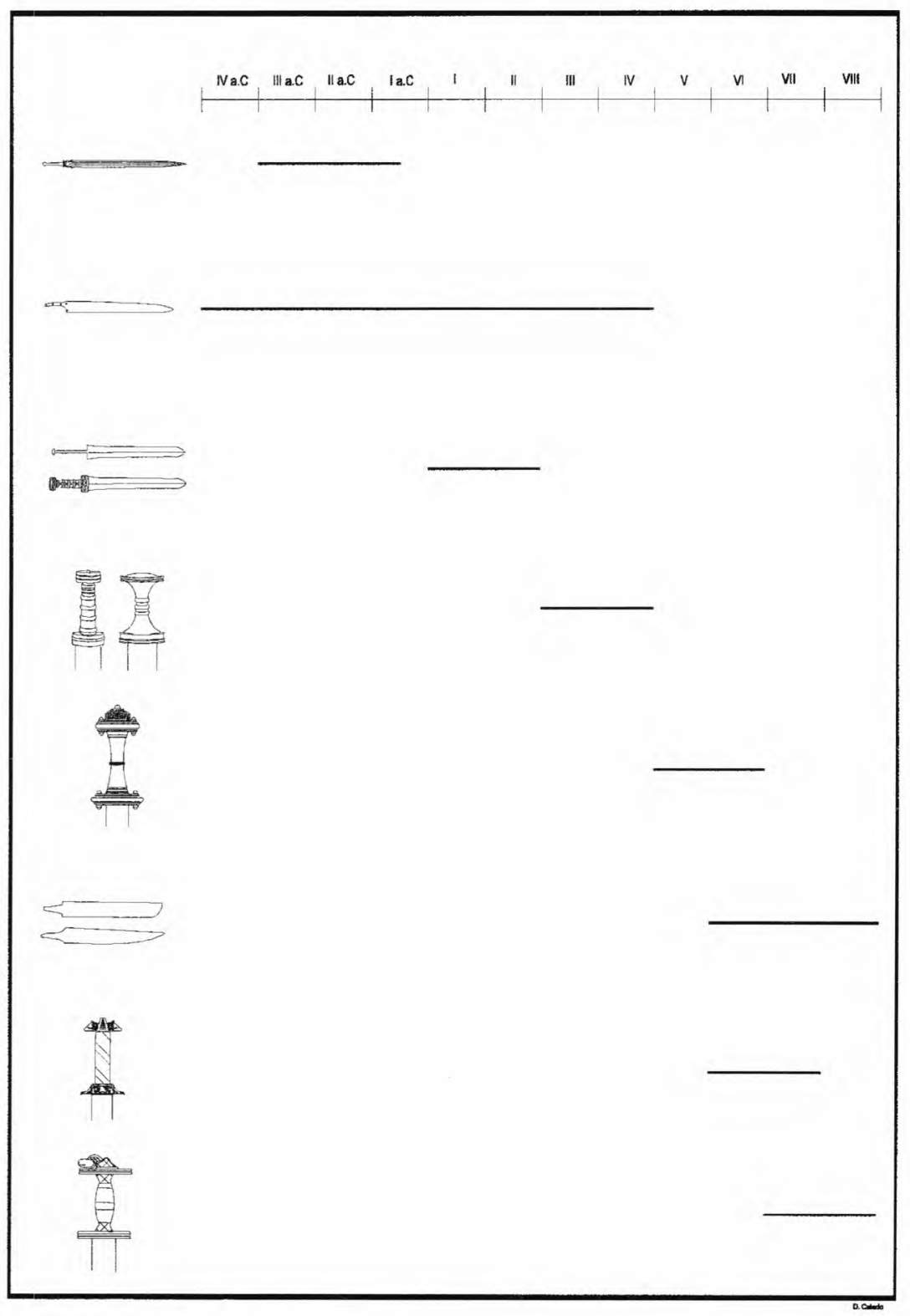




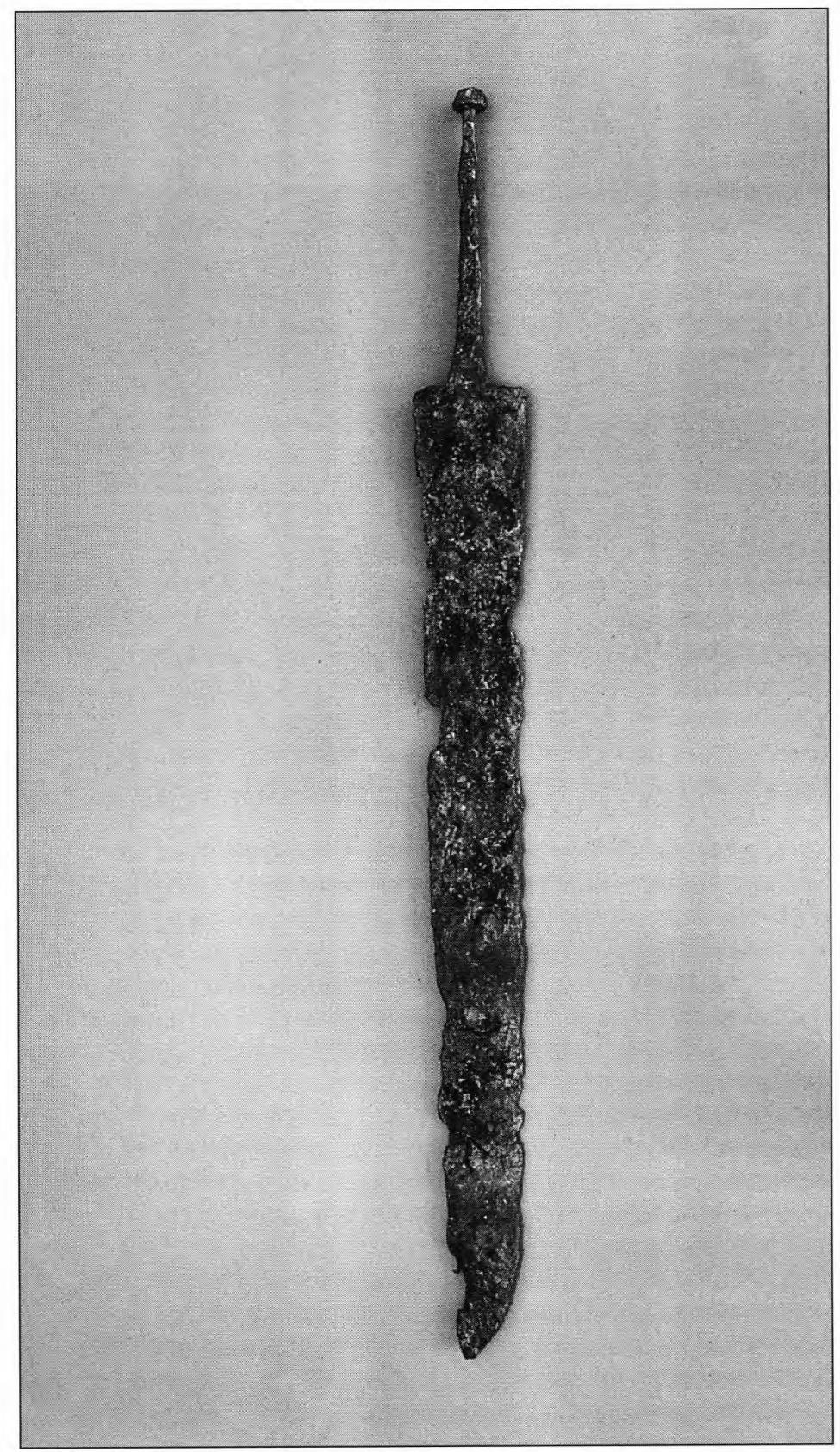

Fото 1 - Espada em ferro de dois gumes, do século II, do Morgado Dona Menga. A forte deterioração sofrida por um dos gumes provoca a impressão de se tratar de uma espada de um só gume. 


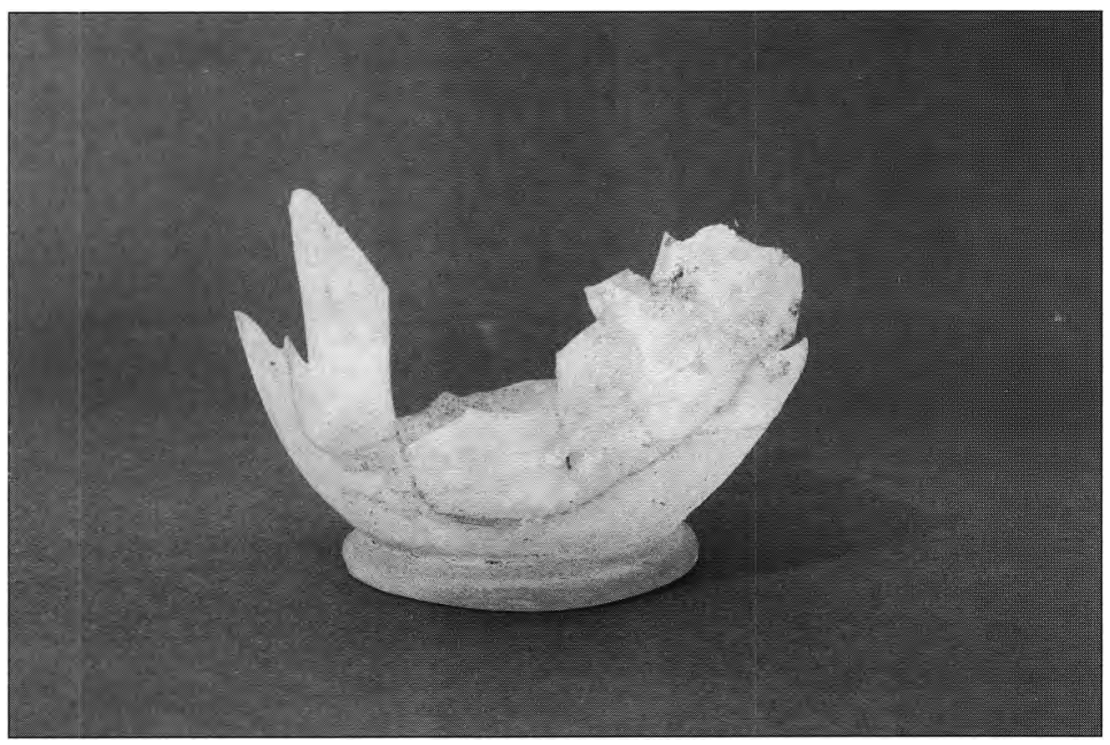

Foto 2 - Copo de vidro, tipo Isings 35, datado do séc. IL

Recuperado da pequena câmara na parede E da cista. 


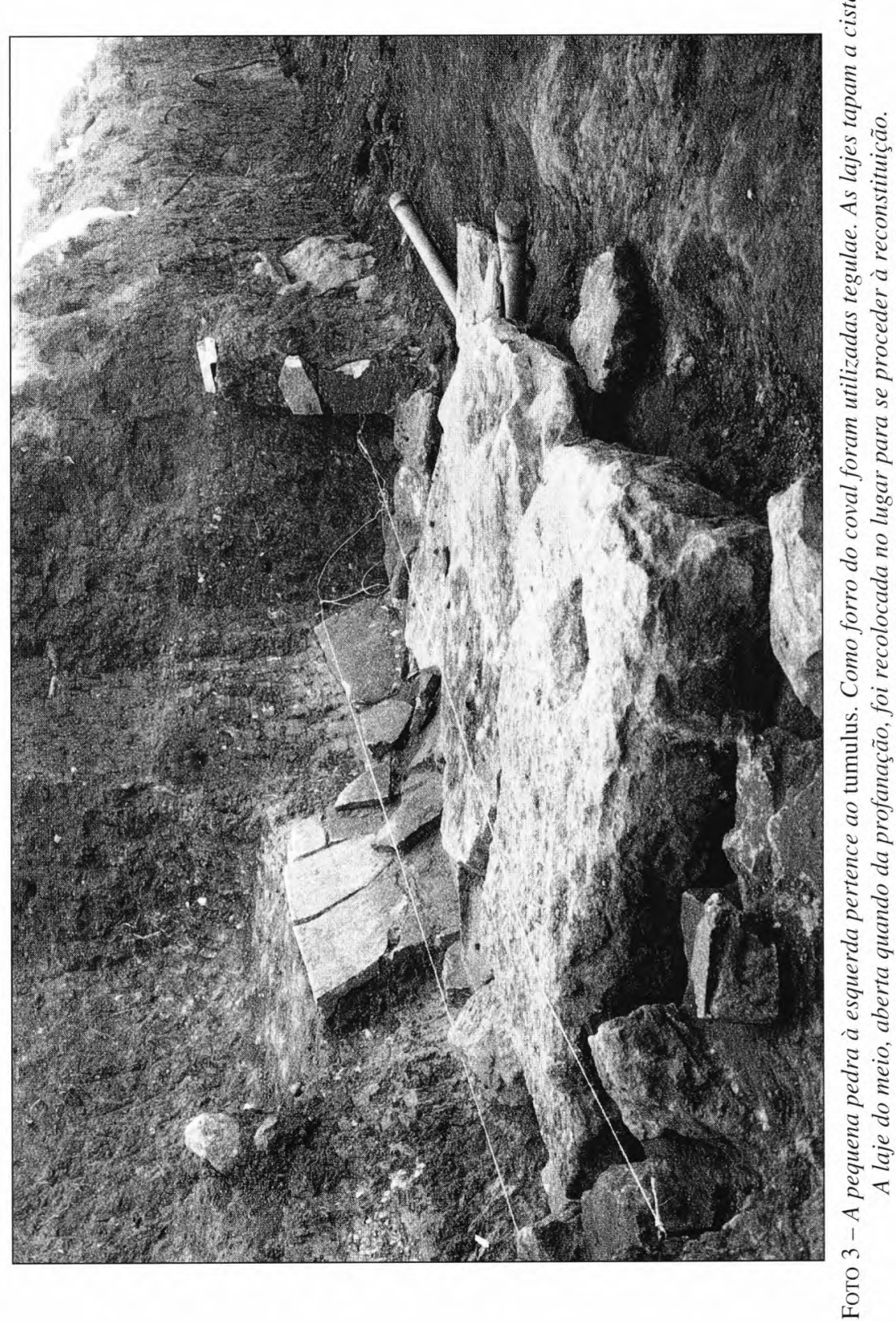

